\title{
Do-It-Yourself medicine? The impact of light cannabis liberalization on prescription drugs
}

\author{
Vincenzo Carrieri $^{\mathrm{a}, \mathrm{b}, \mathrm{c}}$, Leonardo Madio ${ }^{\mathrm{d}, \mathrm{e}}$, Francesco Principe ${ }^{\mathrm{f}, *}$ \\ a Department of Law, Economics and Sociology, "Magna Graecia" University, Catanzaro, Italy \\ ${ }^{\mathrm{b}}$ Institute of Labor Economics (IZA), Bonn, Germany \\ c RWI-Research Network, Essen, Germany \\ d Toulouse School of Economics, Universitè Toulouse 1 Capitole, Toulouse, France \\ e CESifo, Munich, Germany \\ ${ }^{\mathrm{f}}$ Erasmus School of Economics, Erasmus University Rotterdam, The Netherlands
}

\section{A R T I C L E I N F O}

\section{Article history:}

Received 4 February 2020

Received in revised form 3 June 2020

Accepted 10 August 2020

Available online 6 September 2020

\section{JEL classification:}

H51

H75

I18

K32

K42

Keywords:

Light cannabis

Self-Medication

Marijuana

Difference-In-Difference

Prescription drugs

CBD

\begin{abstract}
A B S T R A C T
Governments worldwide are increasingly concerned about the booming use of CBD (cannabidiol) products. However, we know little about the impact of their liberalization. We study a unique case of unintended liberalization of a CBD-based product (light cannabis) that occurred in Italy in 2017. Using unique and high-frequency data on prescription drug sales and by exploiting the staggered local availability of the new product in each Italian province, we document a significant substitution effect between light cannabis and anxiolytics, sedatives, opioids, anti-depressants and anti-psychotics. Results are informative for regulators and suggest that bans on light cannabis use would disregard the needs of patients to seek effective reliefs of their symptoms.
\end{abstract}

(c) 2020 The Authors. Published by Elsevier B.V. This is an open access article under the CC BY license (http://creativecommons.org/licenses/by/4.0/).

\section{Introduction}

The cannabis market has gained momentum worldwide. Ranging from recreational and medical marijuana to cannabis-derived products- such as CBD (cannabidiol), a relaxant compound of cannabis- its consumption is boom-

\footnotetext{
* Corresponding author at: Erasmus School of Economics, Erasmus University Rotterdam, Burgemeester Oudlaan 50, 3062 PA Rotterdam, The Netherlands.

E-mail addresses: vincenzo.carrieri@unicz.it (V. Carrieri), leonardo.madio@tse-fr.eu (L. Madio), principe@ese.eur.nl (F. Principe).
}

ing around the World. In Europe, marijuana is the most used illicit drug, with approximately $20 \%$ of individuals aged 15-24 having used it in 2018 (ECCMDA, 2019). ${ }^{1}$ More recently, low-strength versions of cannabis such as hemp (or industrial hemp), rich in $\mathrm{CBD}$, have also become widely

\footnotetext{
1 In the US, ten states and the District of Columbia allowed for recreational use of cannabis and many others approved medical marijuana laws. As of 2018, Canada passed a law to remove restrictions on production, possession, and consumption of marijuana. In Europe, instead, most states have a strong stance against both versions of cannabis (ECCMDA, 2019).
} 
popular and sold in the form of herbal cannabis (referred to as light cannabis, hereafter), lotions, extracts and candies. A major case of interest is Italy, a country with a conservative view on cannabis, but in which "light cannabis shops" unexpectedly blossomed due to a loophole in the legislation and received massive media and political attention. ${ }^{2}$ With the 2018 Farm Bill, hemp was removed from the definition of marijuana of the Controlled Substances Act and similar products have become available in the US as well, where this industry is expected to be worth $\$ 20$ billion by 2024 (BDS Analytics, 2019).

Despite the considerable interest that these products have received, little is known about the impact of this CBD market and several concerns have been raised regarding the health effects of their use. While, as pointed out by the National Academies of Sciences, Engineering, and Medicine (2017), CBD might not present itself as a risk for human health, this is certainly the case of its misuse to treat serious disorders. In May 2019, just before launching a public hearing with experts on CBD, the Food and Drug Administration (FDA) issued a warning that "misleading and false claims associated with CBD products may lead consumers to put off getting important medical care, such as proper diagnosis, treatment, and supportive care" (FDA, 2019). ${ }^{3}$ Likewise, due to high uncertainty, in 2019 New York City banned CBD-derived food and drinks, whereas several states (i.e., Kansas, Indiana, Louisiana, Texas, and more recently North Carolina) announced or enforced a ban on light cannabis (The New York Times, 2019). A similar hard stance on light cannabis was proposed by the Italian National Health Council (CSS) in 2018. The CSS expressed its concern about the safety of products based on cannabis inflorescence and suggested a ban on the commercialization of the product. In their statement, the CSS raised concerns about the impossibility of monitoring individual users, its effects in the short- and long-term, especially for some vulnerable consumers (e.g., minors, pregnant women, patients with other pathologies).

This paper aims to reach a more in-depth understanding of the "hidden" use of light cannabis and attempts to investigate how people have reacted to the introduction of this new and potentially risky product in the market. On the one hand, as already pointed out by previous studies (e.g. Carrieri et al., 2019), light cannabis can be a substitute for street marijuana and thus generate spillovers on the illegal market. On the other hand, for its relaxant effects, this product can be regarded as a substitute for existing drugs and induce self-medication.

\footnotetext{
2 In May 2019, the industry received massive media and political attention when the Italian Ministry of Interior, Matteo Salvini, started a crusade against local retailers. Local retailers were accused of being "places of mass miseducation" and helping the transition to real drugs (Reuters, 2019).

3 In 2019, the US FDA issued FAQs regarding hemp and the recently approved the Farm Bill (2018). Responding to the question n. 4 "Aside from Epidiolex, are there other $C B D$ drug products that are FDA-approved? What about the products I've seen in stores or online?", FDA stated that "We are aware that some firms are marketing $C B D$ products to treat diseases or for other therapeutic uses, and we have issued several warning letters to such firms."
}

To explore this second channel, we exploit a unique case of unintended liberalization that occurred in Italy in 2017 when light cannabis was unexpectedly allowed to circulate in the market. ${ }^{4}$ Moreover, we use a unique dataset that combines the local availability of this light cannabis across Italian provinces and monthly sales of a large set of prescription drugs for which CBD is often advertised to be effective by producers. These include opioids, anxiolytics, sedatives, anti-migraines, anti-epileptics, anti-psychotics and anti-depressants.

Several features of the Italian case of liberalization make it an ideal setting to explore the causal substitution effect between light cannabis and prescription drug consumption. In December 2016, the Italian government passed a law (Law 242/16) to facilitate the cultivation of industrial hemp in Italy. Due to a loophole in the legislation, the law rendered "not illegal" the large-scale commercialization of the cannabis flower (light cannabis) in the absence of psychotropic effects $(0.2-0.6 \%$ THC). Given the unintended scope of the liberalization, the product was sold as a collector's item and not as a product suitable for human consumption, since May 2017. Critically, due to a lack of anticipation effects, this policy shock provides a plausibly exogenous variation in the policy setting. Indeed, this allows us to test the substitution between existing drugs and light cannabis in the absence of institutional adaptation and potential confounding factors (such as changes in national or local health policies).

A second critical aspect is that the liberalization was accompanied by territorial heterogeneity in the market availability of the product. The presence of light cannabis shops was primarily driven by the morphological and geographical conditions of the territory that made the cultivation of cannabis crops more suitable (see e.g., Carrieri et al., 2019). The first retailers of light cannabis were the already existing grow shops that, before the law was enacted, were selling products related to the cultivation of industrial hemp and, after the change in the legislation, began selling light cannabis exploiting large economies of scope. Subsequently, the commercialization of light cannabis flourished at a different pace across provinces. As the market availability of the product was not linked to the demand for illegal or medical marijuana as well as of pharmaceuticals, the market entry of these retailers can be regarded as plausibly exogenous in our setting.

To identify the effect of interest, we exploit the idiosyncratic availability of light cannabis in the 106 NUTS-3 Italian provinces in a staggered difference-in-differences (DiD) framework in the period of time surrounding the approval of the law. We find that the local availability of light cannabis led to a significant decrease in the number of dispensed boxes of anxiolytics by approximately $11.5 \%$, a reduction of dispensed sedatives by $10 \%$ and a reduction of dispensed anti-psychotics by $4.8 \%$. More nuanced but still

\footnotetext{
4 Another interesting case, which dealt with indoor prostitution, is provided by Cunningham and Shah (2018). The authors study the effects of a Rhode Island District Court ruling, which unexpectedly decriminalized indoor prostitution, on several outcomes such as sexual infections and violence, amongst others.
} 
significant effects are found for anti-epileptics (-1.5\%), antidepressants $(-1.2 \%)$, opioids $(-1.2 \%)$, anti-migraines $(-1 \%)$. An event study specification shows that the substitution between these pharmaceuticals had a larger effect starting from the third month after the introduction of the product in the local market and remains statistically significant also after six months post-liberalization. This is consistent with a learning process and the dynamics of self-medication, which may stem from the need to be aware of the local market availability of the product, experimentation, and finally, more substantial partial or full self-medication. This interpretation is further corroborated by anecdotal evidence from Google Trends, which shows an increasing number of queries on the potential clinical effects of light cannabis after the policy. The figure indicates that patients might have searched for information regarding the new product and their potential relaxant effects when this became available.

Finally, we find that drug prescriptions across provinces did not trend differently for up to six months prior to the light cannabis seller entry in the province, thus reinforcing our identification strategy. These results are robust in a number of checks, including alternative model specifications, randomization tests based on fake treatments and placebo regressions using drugs for which an a priori case of substitution with light cannabis cannot be made. In addition, we also perform a decomposition based on the recent contribution on difference-in-difference methods in the presence of a staggered rollout of the treatment, as provided by Goodman-Bacon (2018).

Our findings contribute to several streams of literature. Specifically, they relate to studies on the substitution effects induced by marijuana legalization. Dinardo (2001) and Crost (2012) used minimum drinking age regulations to show clear substitution patterns between alcohol and marijuana. Powell et al. (2018) show that medical marijuana laws, and in particular, the number of marijuana dispensaries, are associated with fewer opioid overdoses. Similar patterns were already documented by Shy (2017), Liang et al. (2018); Chan et al. (2020); Smith (2020) and McMichael et al. (2020). Bradford and Bradford (2016; 2017; 2018) studied how the availability of medical marijuana impacted on Medicare and Medicaid drug prescriptions in the US, with a significant reduction for those related to pain relief, anxiety, nausea, depression, psychosis and sleep disorders.

Our contribution to this stream of literature is threefold. First, this represents the first-ever evidence from Europe on the substitution effects induced by a compound of cannabis, the CBD. As the product is increasingly available in other European countries (e.g., Belgium, Germany), our results provide relevant implications for policymakers. Second, while there is a high degree of variation in medical and recreational marijuana laws in the US - where some states adopted a more liberal (almost recreational marijuana) approach, and others a stricter one (where people need a terminal diagnosis to get a prescription)- the Italian experience has been both liberal and strict at the same time. More importantly, the loophole in the legislation was homogenous in the entire country, although the local availability of the product was initially heterogeneous between local areas. Arguably, this represents a suitable setting to explore medical substitution between light cannabis and several different types of prescription drugs by exploiting territorial heterogeneity in product availability. Third, substitution effects arising from medical marijuana laws in the US require a doctor's prescription. Despite the fact that the physician's involvement might be quite limited, i.e., because of their role as gatekeeper, this entails, in any case, a kind of supply-side driven substitution ${ }^{5}$. In our case, such a substitution is purely consumer-driven as it cannot involve the recommendation of a medical professional. This is because light cannabis is sold as a technical and collector's item and, hence, virtually considered not suitable for human consumption.

Moreover, our paper adds to the literature on the economics of these (potentially) risky behaviors (for a review, see e.g.,Cawley and Ruhm, 2012). Traditionally, these behaviors, and in particular addictive ones (such as heavy drinking, smoking, and drug abuse), have mostly been considered as a consequence of imperfectly rational individual's choices, time-inconsistent preferences or triggered by incomplete information regarding possible risks. ${ }^{6}$ More recently, risky behaviors have been associated with the so-called "death of despair" (Case and Deaton, 2015). However, these may also emerge as a form of rational self-medication for symptoms not effectively treated by currently available drugs. This is the new perspective highlighted by Darden and Papageorge (2018), who recently proposed a novel rational interpretation that was consistent with a utility-maximizing framework and tested it empirically. They find that the availability of new and better drugs for depression has led to a reduction of forms of self-medication, such as alcohol, in the US. Our study contributes to this literature from a novel angle by testing the effect of the availability of a new product suitable for selfmedication on existing drug consumption. The unintended nature of this liberalization offers the unique opportunity to test for the presence of self-medication by exploiting an exogenous variation in the availability of the product.

Lastly, our analysis also complements the literature concerned with the effect of marijuana liberalization. This has already shown effects on other outcomes, e.g., crime (Carrieri et al., 2019; Chang and Jacobson, 2017; Gavrilova et al., 2017; Chu and Townsend, 2018; Dragone et al., 2019, inter-alia), traffic fatalities (Anderson et al., 2013; Hansen et al., 2020a), teenager use (Wen et al., 2015, Červený et al., 2017), fertility (Baggio et al., 2020), body weight and obesity (Sabia et al., 2017) but it lacks studies on drug consumption and self-medication.

\footnotetext{
${ }^{5}$ In the US, physicians in states where there is cannabis liberalization can sign a state form certifying that the patient has a qualifying medical condition to buy cannabis at dispensaries. However, their involvement in suggesting a cannabis-based therapy may be very limited and only related to their role as gatekeepers.

${ }^{6}$ Starting with seminal contributions of Becker and Murphy (1988), the literature on rational addiction has been broadly tested on different outcomes, e.g., alcohol (Baltagi and Griffin, 2002; Dragone, 2009), cigarettes (Chaloupka, 1991; Becker et al., 1994), cocaine (Grossman and Chaloupka, 1998), and opium (Van Ours, 1995).
} 
The paper is structured as follows: In Section 2, we present the policy reform that occurred in Italy. In Section 3 , we discuss our data and the identification strategy. In Section 4 , we present our main results, followed by some sensitivity analyses and robustness checks of these results in Section 5. In the final section, we present some concluding remarks.

\section{Institutional setting}

Italy has a long historical tradition of the cultivation of cannabis. One of the earliest large cannabis cultivations dates back to the 1 st century A.D. (Mercuri et al., 2002). In the 1940s, Italy was the second-largest producer of industrial cannabis worldwide. Despite this fact, marijuana cultivation, possession, and sale remain illegal, except for its industrial and medical use.

However, in 2016, the government passed Law $242 / 2016$, which was intended to remove some restrictions on cultivation, transformation, and commercialization of industrial hemp, a strain of Cannabis sativa, widely used for textiles, clothing, and food. For its use, hemp is not classified as a drug as it is (almost) free of the psychoactive cannabis compound (THC). The latter should be kept below 0.6 , and it is rich in CBD, a relaxant compound. Failing to account for this limit would imply narcotic effects and hence be subject to confiscation, closure, and risk of conviction for drug dealing. In 2018, as demand for CBD products grew, Italy had approximately 4,000 ha of land dedicated to hemp cultivation, that is, ten times more than in 2013.

The law, however, did not explicitly intervene on the commercialization of the cannabis flower, leaving a loophole in the legislation. As a result, as not explicitly forbidden, herbal cannabis was essentially liberalized. From May 2017 onwards, once the inflorescence phase was over, several startups exploited this grey and completely unregulated market and started selling light cannabis as a "technical product", that is, as a collector's item not meant to be smoked or consumed. The same retailers also started selling other CBD-based products such as oil, leaves, extracts, food and beverage.

Interestingly, the local market availability of light cannabis did not arise simultaneously in all geographical areas of the national territory. Due to the unannounced liberalization, local availability in the first months after the policy mainly affected those areas previously served by grow shops, that is, shops selling seeds and cannabisrelated products. As documented elsewhere (e.g., Carrieri et al., 2019), these grow shops were mainly concentrated in those areas in which industrial cannabis cultivation was more likely due to the geographical and morphological conditions of the territory. As a result, the first retailers selling the product were those grow shops that, before the policy shock, were already supplying industrial hemp and items for its cultivation and that could exploit existing supply chains and networks.

Fig. 1 depicts this staggered entry into the market during the period covered by this study. In May 2017, 22 out of 106 provinces were served by at least one light cannabis retailer. After a first introductory phase, light cannabis shops blossomed, thereby becoming a "social phenomenon". Tobacco and herbalist shops, parapharmacists and automatic machines began selling this product as well and expanded their local coverage. As shown by Fig. 1, by February 2018, the number of provinces reached 87 and the entire country was gradually covered by retailers throughout 2018. In 2019, more than 1000 shops were open.

Interestingly, in May 2019, the situation in the market changed dramatically. The former Minister of the Interior, Matteo Salvini, announced a crackdown on this herbal cannabis sales and several retailers had their products confiscated as a precaution. The reason was that, in several cases, the flowers contained more THC than that allowed by the law to avoid being considered as an intoxicating substance. In turn, this triggered intervention from the police. ${ }^{7}$ In the same month, the Court of Cassation, Italy's Supreme Court, aimed to close the loophole in the legislation by deciding to impose a ban on the sales of cannabis derivatives such as "oil, leaves, inflorescences, and resin". However, the Court's ruling left a backdoor open for a mild interpretation of the law for those CBD-derived products free of narcotic effects, creating more uncertainty in the market. Akin precautions, many companies and shops shut down in June 2019. This paper thus exploits this phenomenon during the period in which the market was entirely left unregulated. Fig. 2 provides a time framework regarding our study, which covers market entry data from May 2017 to February 2018.

\section{Data and methods}

We use a unique longitudinal dataset recording monthly drug sales and mapping the local market availability of retailers selling light cannabis at the province level (106 NUTS-3 provinces) over the period from January 2016 to February 2018. ${ }^{8}$ Data on these dispensaries were collected using the Archive Internet Wayback Machine on the websites of the four main producers of light cannabis in 2017. These were then matched with data on prescription drug sales obtained by Federfarma, the Italian association of pharmacy owners. Our data tracks the pharmaceutical expenditure of the Italian Local Health Authorities (ASLs) and covers more than $95 \%$ of Italian pharmacies. As one or more ASLs can serve a given province, data were aggregated at the province level (106 provinces).

Our dataset tracks all "Class A" drugs dispensed by the Italian NHS containing active ingredients often used to treat symptoms for which marijuana can also provide relief or, at least, relaxant effects. Specifically, these refer to opi-

\footnotetext{
7 This was not the case of CBD, for which no limitation in its quantity per milligram existed.

8 We collected monthly information on the entry in a market in each Italian province by having access to archived copies of their early pages of the four main producers in 2017 (Easyjoint, Marymoonlight, RealHemp, XXXJoint) using the Internet Archive Wayback Machine https://archive.org/web/. Data were collected monthly from May 2017 (first entry in the market) and using the last accessible page for each month. When data were not available, the average number of retailers between the months with missing information was imputed.
} 


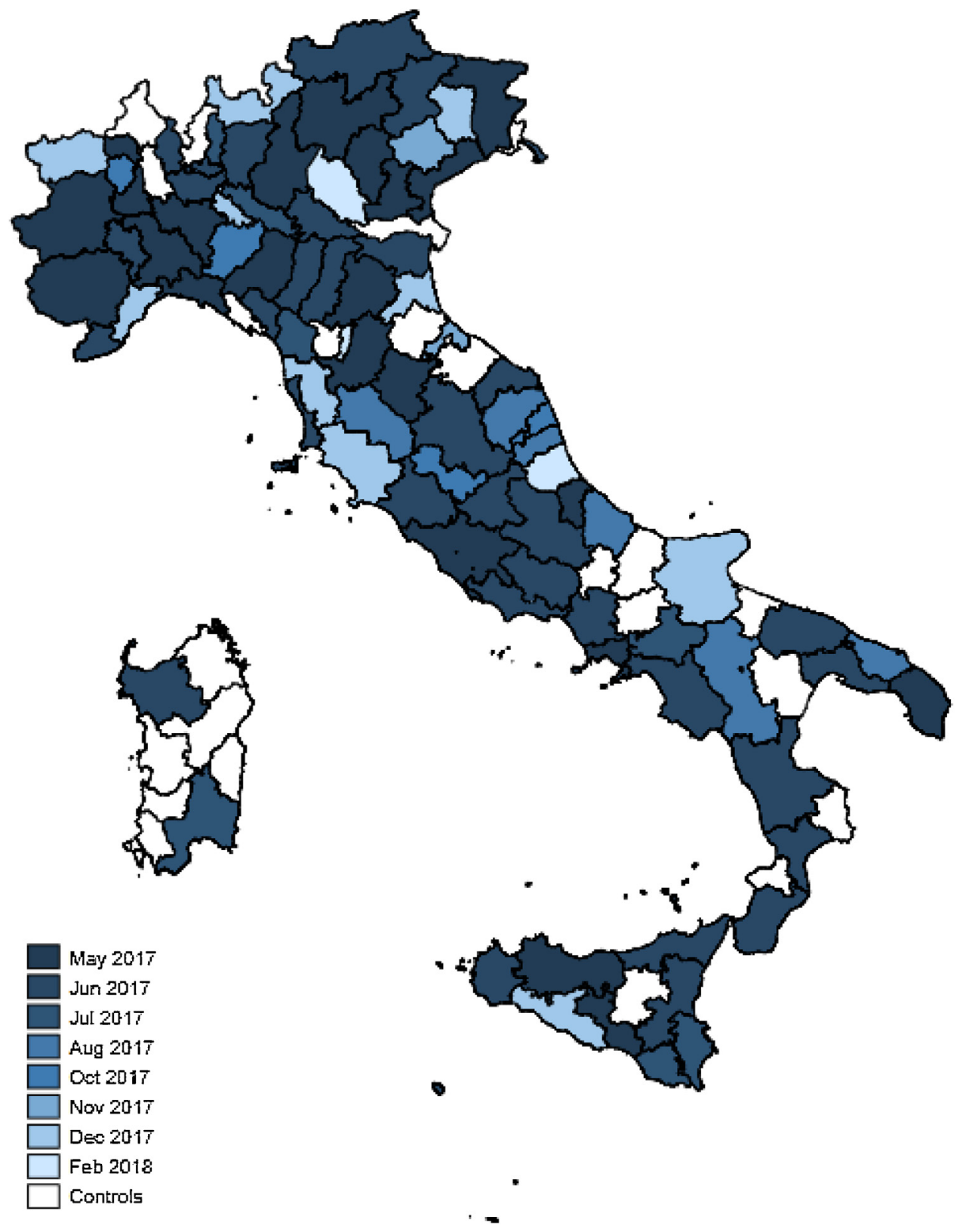

Fig. 1. Timing of local availability of light Cannabis.

The map reports the different timing of local availability of light cannabis in the 106 provinces we consider starting from May 2017. Data are retrieved from the Internet Wayback Machine Archive.

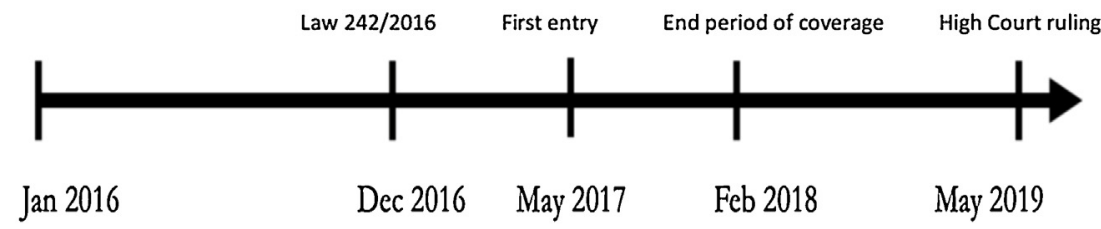

Fig. 2. Timeline.

Our study covers monthly data from January 2016 to February 2018. The Law (242/2016) was approved on December 2016. In May 2017, the first entry in the market occurred (see Fig. 2). In May 2019, Italy's High Court decided about the possibility to commercialize the product. 
Table 1

Descriptive statistics.

\begin{tabular}{|c|c|c|c|c|}
\hline Variable & ATC/DDD & Description & Mean & Std. Dev. \\
\hline Sedatives & N05C & Monthly number of dispensed sedatives and hypnotic drugs per province (boxes) & 28.20 & 109.73 \\
\hline Anxiolytics & N05B & Monthly number of dispensed anxiolytics per province (boxes) & 72.52 & 359.45 \\
\hline Anti-epileptics & N05A & Monthly number of dispensed anti-epileptics per province (boxes) & $18,459.67$ & $21,474.39$ \\
\hline Opioids & N02A & Monthly number of dispensed opioids per province (boxes) & $12,610.91$ & $13,065.20$ \\
\hline Anti-migraines & N02C & Monthly number of dispensed anti-migraines per province (boxes) & $2,504.26$ & $2,626.09$ \\
\hline Anti-psychotics & N05A & Monthly number of dispensed anti-psychotics per province (boxes) & $4,802.44$ & $5,903.55$ \\
\hline Anti-depressives & N06C & Monthly number of dispensed anti-depressives per province (boxes) & $27,198.25$ & $26,290.68$ \\
\hline Nr. Observations & & 106 provinces $X 26$ months & 2756 & \\
\hline
\end{tabular}

Note: data are made available by Federfarma for all "Classe A" drugs dispensed by the Italian NHS. Sales are registered based on the WHO ATC/DDD, which classifies drugs based on a technical unit of measurement called the Defined Daily Dose (DDD).

oids, anxiolytics, hypnotics and sedatives, anti-migraines, anti-epileptics, anti-psychotics and anti-depressives, as standardized for the ATC/DDD classification of the WHO Centre for Drug Statistics Methodology. This classification standardizes drugs based on the active principle and organs they treat (Anatomical Therapeutic Chemical Classification System ATC) and of the Defined Daily Dose (DDD). The latter accounts for "the average maintenance dose per day for a drug used for its main indication in adults".

Importantly, these drugs require a doctor's prescription, which is typically provided in-person by the physician, and is available either free of charge or with a minimal patient co-payment. ${ }^{9}$ Moreover, there are two important caps which are designed to regulate individual drug consumption and make it strictly adherent to standardized therapies, as defined by the ATC/DDD system. First, there is a cap on the number of boxes that a doctor can prescribe, which is typically 2 for the drugs considered. Second, there is a cap on the length of the period a prescription can be refilled, which is typically 30 days, and this ensures compliance with the dosing interval. In our framework, these caps allow us to measure the substitution effects in terms of DDDs for each ATC and, thus, rule out any intertemporal changes in the number of monthly packages sold. Finally, our dataset tracks all prescriptions that translated into a final sale in each province.

The pharmaceuticals we consider have shown patterns of substitutability with medical marijuana (Bradford and Bradford, 2016; 2017; 2018), which however presents some differences with respect to the light one. For instance, medical marijuana, rich in THC, is largely used to treat chronic pain, glaucoma, insomnia and anxiety. Instead, for its clinical effects, CBD is often associated with antipsychotic, analgesic, anti-inflammatory, anti-arthritic, and anti-neoplastic properties and is used to treat inflammations, migraines, depression, and anxiety (Blessing et al., 2015; CIBG, 2018). However, CBD-based products have come under scrutiny in the US for misleading claims made by some $\mathrm{CBD}$ producers relative to its effectiveness in

\footnotetext{
9 According to Federfarma (2018), “Classe A “drugs are the most consumed drugs in Italy, accounting for approximately 52\% of the entire market for pharmaceutical products (which also include dietary products, herbs, para-pharmaceuticals, and products for health and beauty care). Co-payments, which depends on the regional co-payment settings and individuals' equivalent income, range from 1 euro per box to 4 euro per the entire prescription.
}

treating the above pathologies. Apart from Epidiolex, a drug recently approved by the FDA to treat rare forms of epilepsy, no other drug contains CBD. Opioids were also included as, according to recent anecdotal evidence, Canadian veterans started substituting opioids (along with benzodiazepines) with marijuana after their introduction of medical marijuana in Canada to treat anxiety, insomnia and pain relief. Several scholars also documented similar patterns of substitutability with medical marijuana (e.g.,Bradford and Bradford, 2016, 2018; Shy, 2017; Bachhuber et al., 2014).

Table 1 describes the main variables we use and shows a large heterogeneity across drug categories in the number of dispensed drug packets. On a monthly average, the Italian NHS provides reimbursement for 28 packets of sedatives and 72 boxes of anxiolytics per province. Much higher numbers are documented for anti-epileptics $(18,460$ packets), antipsychotics (4802 packets) and anti-migraines (2504 boxes). With 27,198 packets sold on average, antidepressants represent the drug with the largest sales in our sample. ISTAT, the Italian National Institute of Statistics, estimates that more than 2.4 million Italians suffered from mental health problems in 2015, and approximately 1.3 million presented symptoms of depression (ISTAT, 2018).

Interestingly, opioids, which are widely used in the US and Canada for acute and chronic pain relief but which have severe side effects such as dependency and sedation, show lower numbers, accounting for an average monthly sale at the province level of 12,610 packets. Although the number of prescriptions increased in recent years, these numbers depict the general level of skepticism among Italians concerning this drug.

Finally, by matching this information with those available from light cannabis local retailers, we obtained a balanced panel with a total of 2756 province-month observations.

\section{Identification strategy}

In order to identify the causal effect of light cannabis on the prescriptions of drugs, we employ a staggered DiD, which exploits the idiosyncratic availability of light cannabis in a given province. ${ }^{10}$ Thus, our identification

\footnotetext{
10 In text context of substances, a similar identification strategy based on a staggered rollout of the opium policy in the Java during the period 1875-1904 was provided by Van Luijk and Van Ours (2001). Similarly,
} 
Table 2

Difference-in-differences regression.

\begin{tabular}{|c|c|c|c|c|c|c|c|c|}
\hline & $\begin{array}{l}(1) \\
\text { All }\end{array}$ & $\begin{array}{l}(2) \\
\text { Sedatives }\end{array}$ & $\begin{array}{l}\text { (3) } \\
\text { Anxiolytics }\end{array}$ & $\begin{array}{l}\text { (4) } \\
\text { Anti-epileptics }\end{array}$ & $\begin{array}{l}(5) \\
\text { Opioids }\end{array}$ & $\begin{array}{l}\text { (6) } \\
\text { Anti-migraines }\end{array}$ & $\begin{array}{l}\text { (7) } \\
\text { Anti-psychotics }\end{array}$ & $\begin{array}{l}(8) \\
\text { Anti-depressives }\end{array}$ \\
\hline \multirow[t]{2}{*}{ DiD } & $-0.016^{* * *}$ & $-0.095^{*}$ & $-0.114^{* *}$ & $-0.015^{* * *}$ & $-0.012^{* *}$ & $-0.009 *$ & $-0.048^{* *}$ & $-0.012^{* * *}$ \\
\hline & 0.004 & 0.053 & 0.055 & 0.004 & 0.005 & 0.005 & 0.018 & 0.003 \\
\hline Controls & yes & yes & yes & yes & yes & yes & yes & yes \\
\hline Year FE & yes & yes & yes & yes & yes & yes & yes & yes \\
\hline Month FE & yes & yes & yes & yes & yes & yes & yes & yes \\
\hline Province FE & yes & yes & yes & yes & yes & yes & yes & yes \\
\hline$N$ & 2756 & 2756 & 2756 & 2756 & 2756 & 2756 & 2756 & 2756 \\
\hline
\end{tabular}

Log-transformation of the dependent variable. S.E. clustered at the province-level in italics. ${ }^{* * *},{ }^{* *},{ }^{*}$ indicate statistical significance at $1 \%, 5 \%$, and $10 \%$ respectively.

relies both on the staggered timing of the product availability and the provinces without any retailer as the control group. ${ }^{11}$ More formally, we estimate the following equation:

$Y_{i t}=\alpha+\sum_{k} \beta_{k}$ Entry $_{i k}+\delta X_{i t}+\gamma_{i}+\mu_{t}+\varepsilon_{i t}$

where $Y_{i t}$ is the number of packets of dispensed drugs (i.e., opioids, anxiolytics, sedatives, anti-migraines, antiepileptics, anti-depressants and anti-psychotics) reimbursed by NHS at the time $t$ in the province i, Entry is an indicator that takes value 1 if at least a cannabis retailer has entered in all periods $k<t$ in province $i$. $\gamma$ and $\mu$ are province and time (month and year) fixed effects, $\varepsilon$ represents the error term. $X_{i t}$ is a vector of controls for province population size and density and a dummy for the post-May period to take into account eventual changes that occurred at the national level after the unintended liberalization. Our coefficient of interest is $\beta$, which captures the monthly change in the sales of dispensed drugs due to the local availability of light cannabis.

The credibility of our identification strategy relies on the natural experiment which characterized the policy. As discussed, the policy was unannounced and concerned hemp, a product that, when sold as light herbal cannabis, differs in its composition from both recreational and medical marijuana. Thus, the entry of light cannabis retailers in a local market can be regarded as plausibly exogenous as it was not linked to the demand for illegal or medical marijuana as well as pharmaceuticals. Moreover, the possibility of endogenous entry is essentially ruled out for several reasons. First, the precise nature of the unintended liberalization process rendered any anticipatory effect to be implausible. The law was approved in December 2016 and, after an early cultivation phase, the product was first marketed in May 2017. s, the local availability during the period under investigation mainly depended on the geographi-

Dragone et al. (2018) exploit the staggered adoption of the recreational marijuana laws in the states of Washington and Oregon to study its effects on crime.

11 In our identification strategy, we cannot rule out cross-province movements to buy light cannabis, as recently shown by Hansen et al. (2020b). However, in the period we consider, it is implausible that people managed to know about the local availability of light cannabis in a different province and systematically move to that province accordingly to buy the product. As a result, in our setting, cross-province shopping does not represent a concrete issue. cal presence of grow-shops before the policy change. The latter are retailers specialized in industrial hemp, which were the first to sell light cannabis after the liberalization by exploiting large economies of scope and their existing supply chains (see, for example, Carrieri et al., 2019). Finally, we make use of high-frequency data to focus on a narrow time window surrounding the implementation of the (unintended) policy (May 2017 - February 2018). This allows us to rule out potential changes in national and local health policies concerning prescribed drugs and systematic changes in the prescription choices of medical doctors. This is because any change requires time to be fully operational and extensively included in medical guidelines and protocols.

More formally, our empirical analysis relies on the classical DiD's identifying assumptions in the pre-liberalization periods, that is, the existence of a common trend in drug prescriptions. In our setting, it implies assuming that those provinces experiencing different timings in the local availability of light cannabis (treatment group) and those provinces never served by cannabis retailers in the period we consider (control group) should have observed the same pre-policy trends for all drug categories. In Section 5, we find strong support for this hypothesis by performing a visual inspection of common trends and more formal tests such as placebo regressions and falsification tests based on alternative approaches to statistical inference.

\section{Results}

Our results are reported in Table 2 for all pharmaceuticals for which medical marijuana can be considered as a substitute or adjuvant therapy. For ease of interpretation, the dependent variable is expressed in logs. This allows us to interpret the DID-coefficient as the average percentage change in the monthly number of dispensed drugs resulting from the local availability of light cannabis.

For all drug categories, we document a significant and negative effect. Specifically, as the market availability of light cannabis became possible due to the entry of at least one retailer in a given province, the number of dispensed drug sales fell by approximately $1.6 \%$, on average. The extent of this reduction reveals a considerable degree of heterogeneity. The boxes of anxiolytics prescribed by doctors and sold by pharmacies significantly decreased by $11.4 \%$, the sedatives consumption decreased by approximately $10 \%$, while the number of anti-psychotics decreased 
by $4.8 \%$. These drugs account for the most considerable reductions. Interestingly, these are also the type of drugs for which CBD - but not light cannabis itself - is recognized or advertised as having a clinical effect, that is, to treat anxiety and psychosis (Blessing et al., 2015; CIBG, 2018). This is intuitively explained by the relaxant properties of $\mathrm{CBD}$, which is often used to treat sleep disorders. Moreover, the large coefficients that we observe for sedatives and anxiolytics can be explained by the marketing strategies for cannabis and CBD-related products sold, which are typically advertised for its relaxant effects. These marketing strategies fueled a government investigation in the US. This result may suggest that patients decided to (partially) abandon a conventional medical treatment and switched to light cannabis to treat symptoms such as anxiety and sleep disorders.

More relatively nuanced yet, significant reductions are found for other pharmaceuticals, which appear to offer a more chronic therapy. These findings are consistent with a self-medication interpretation also for these drugs. There is a mild average monthly reduction in the number of packets for anti-epileptics (-1.5\%), anti-depressants (-1.2\%), opioids $(-1.2 \%)$ and anti-migraines (approximately $-1 \%)$. These are all drugs requiring a constant and consistent therapy, often prescribed by specialists, and for which the switching to an "alternative therapy" based on self-medication may be more problematic, especially for risk-averse individuals. Still, despite the short time window, local market availability of light cannabis and other cannabis-derived products led to a reduction in prescription drugs but with a lower intensity.

Moreover, it is noteworthy that opioids, antidepressants and anti-epileptics are all pharmaceuticals that show severe side effects and can be associated with a social stigma. In Italy, opioids are also generally less prescribed than in the US, where unregulated prescription led to an opioid crisis (Case and Deaton, 2015). Indeed, some patients may have seen in this new product the possibility to seek (partial) relief or improve their quality of life, for instance, by making use of a mostly accessible product which does not require any medical prescriptions and which is perceived to be of regular use (e.g., oils, essences, or even similar to recreational yet illegal cannabis).

An interpretation consistent with the self-medication hypothesis is also anecdotally supported by looking at online information seeking. Fig. 3 provides further support for the use of light cannabis as a form of self-medication using Google Trends statistics. It shows that both the general interest in the product and its use to treat anxiety disorders peaked in the month of the introduction of the product into the Italian market (May 2017) and remained at a higher level in the subsequent period. This supports the idea that people were seeking information online for treating their symptoms before actually switching to the new product.

One can note that our results share some similarities with those found by Bradford and Bradford (2016; 2017). However, there are relevant differences. They showed a larger reduction in drug prescriptions (up to 10-20\%) than ours. These differences can be attributed to a number of causes. First, they focus on some population samples restricted to those eligible for either Medicare Part D or Medicaid, whereas our data refers to the overall number of drug sales (and indeed) prescriptions without age limitation and eligibility constraints. Hence, our results may indicate that substitution effects are lower when estimated on a general population. Second, we focus on a non-medical treatment (i.e. light cannabis) that can be bought without a physician's indication. Indeed, we estimate a demanddriven substitution. With these lenses, our results suggest that a substitution driven by self-medication may be lower than the one also induced by the physician.

\section{Robustness checks}

To assess the robustness of our results, we present results of several checks. First, we restrict the time before the policy. This renders the time windows more symmetrical before and after the policy (May 2016 - February 2018). Despite reducing the number of observations (2332), our main results and intuitions remain unaltered. Estimates of the DID coefficients are reported in the first row of Table 3 for all drug categories we consider. Specifically, the local availability of light cannabis leads to a reduction in the number of dispensed boxes of sedatives by $11.5 \%$, anxiolytics by $12.3 \%$ and anti-psychotics by $4.3 \%$. Consistently with the baseline specification, we find a more subtle but significant effects on other prescribed drugs: the selling of anti-epileptics decreases by $1.5 \%$, whereas those of anti-depressants, opioids, and anti-migraines decrease by approximately $1 \%$.

Second, we include a linear time trend to capture any time-varying confounding factor which might affect our estimates. Estimates of the DID coefficient are reported in the second row of Table 3 and are very similar to those reported in the main model specification. Moreover, we include province-specific time trends. This allows us to allay any remaining concerns regarding provincespecific changes in prescriptions and drugs sale. Results are reported in the last row of Table 3 and are qualitatively similar to those presented in Table 2. However, we observe a reduction in the coefficient of anti-psychotics, which loses significance but remains negative. We thus suggest a more cautious interpretation of this effect.

Third, we test whether the common trend assumption can be credibly maintained. A typical concern which may arise when adopting a DID approach is the presence of prepolicy trends, which may drive the main results. To allay this concern, we make a visual inspection of the trends for provinces experiencing early (May - September 2017) and late (October 2017 - February 2018) local availability in the market and for those provinces never exposed to access to light cannabis during the period we consider. This allows us to verify whether provinces experiencing different timings in the entry of light cannabis retailers followed similar trends in drug sales before the actual liberalization (May 2017). As highlighted in Fig. 4, pre-policy trends are parallel and the post-policy drop in dispensed drugs is consistent with the timing of the local availability in treated provinces, compared to the controls. This supports the credibility of the common trend hypothesis in our setting. 


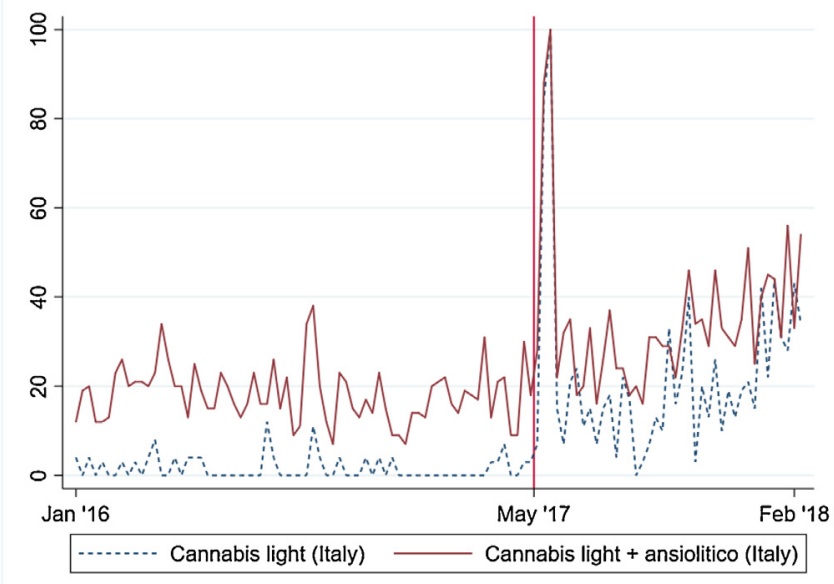

Fig. 3. Google trends queries on "cannabis light" and "cannabis light + anxiolytics" in Italy.

The figure presents the number of Google Search queries on "cannabis light" and "cannabis light + ansiolitico (anxiolytics)" in Italy during the period we considered. In May 2017, when the product was announced, the number of queries had a spike and the number of queries remained at a higher level in the subsequent period.

Table 3

Robustness checks: parameter estimates.

\begin{tabular}{|c|c|c|c|c|c|c|c|c|}
\hline & $\begin{array}{l}(1) \\
\text { All }\end{array}$ & $\begin{array}{l}(2) \\
\text { Sedatives }\end{array}$ & $\begin{array}{l}\text { (3) } \\
\text { Anxiolytics }\end{array}$ & $\begin{array}{l}\text { (4) } \\
\text { Anti-epileptics }\end{array}$ & $\begin{array}{l}(5) \\
\text { Opioids }\end{array}$ & $\begin{array}{l}\text { (6) } \\
\text { Anti-migraines }\end{array}$ & $\begin{array}{l}\text { (7) } \\
\text { Anti-psychotics }\end{array}$ & $\begin{array}{l}\text { (8) } \\
\text { Anti-depressives }\end{array}$ \\
\hline Shorter time & $-0.016^{* * *}$ & $-0.115^{* *}$ & $-0.123^{* *}$ & $-0.015^{* * *}$ & $-0.011^{* *}$ & $-0.010^{* *}$ & $-0.043^{* *}$ & $-0.012^{* * *}$ \\
\hline window & 0.003 & 0.054 & 0.058 & 0.004 & 0.004 & 0.005 & 0.018 & 0.003 \\
\hline Linear trend & $\begin{array}{l}-0.016^{* * *} \\
0.004\end{array}$ & $\begin{array}{l}-0.100^{*} \\
0.052\end{array}$ & $\begin{array}{l}-0.115^{* *} \\
0.055\end{array}$ & $\begin{array}{l}-0.014^{* * *} \\
0.004\end{array}$ & $\begin{array}{l}-0.011^{* *} \\
0.005\end{array}$ & $\begin{array}{l}-0.010^{*} \\
0.005\end{array}$ & $\begin{array}{l}-0.047^{* *} \\
0.018\end{array}$ & $\begin{array}{l}-0.012^{* * *} \\
0.003\end{array}$ \\
\hline Province-trend & $\begin{array}{l}-0.017^{* * *} \\
0.003\end{array}$ & $\begin{array}{l}-0.186^{* *} \\
0.076\end{array}$ & $\begin{array}{l}-0.157^{*} \\
0.093\end{array}$ & $\begin{array}{l}-0.018^{* * *} \\
0.003\end{array}$ & $\begin{array}{l}-0.019^{* * *} \\
0.004\end{array}$ & $\begin{array}{l}-0.012^{* *} \\
0.005\end{array}$ & $\begin{array}{l}-0.020 \\
0.013\end{array}$ & $\begin{array}{l}-0.011^{* * *} \\
0.003\end{array}$ \\
\hline
\end{tabular}

Log-transformation of the dependent variable. S.E. clustered at the province-level in italics. ${ }^{* * *}$, ${ }^{* *},{ }^{*}$ indicate statistical significance at $1 \%, 5 \%$ and $10 \%$, respectively. The first row reports the estimates of the DID coefficient considering a shorter time window (May 2016 - February 2018 ). The second row reports the estimates of the DID coefficient in the presence of a linear trend. The third row reports the estimates of the DID coefficient in the presence of a province-specific trend.

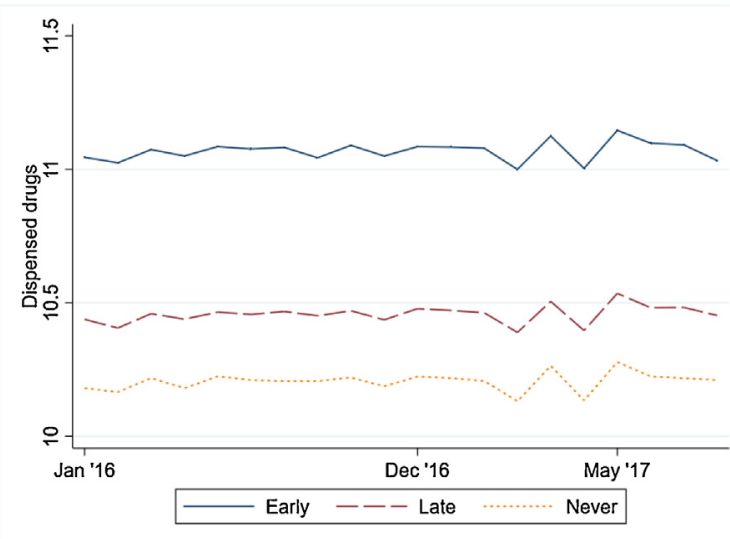

Fig. 4. Common trend.

The figure presents the trends in all dispensed drugs in our dataset (opioids, anxiolytics, sedatives, anti-migraines, anti-epileptics, antipsychotics and anti-depressives) for provinces exposed to early, late and no local accessibility to light cannabis. Early entry refers to local availability during the first 5 months after the first entry (between May and September 2017). Late entry refers to local availability during the last 5 months we observe, which is between October 2017 and February 2018.
Fourth, we perform a placebo test using as dependent variables prescription drugs for which there is no medical evidence of possible substitution patterns with light cannabis. Indeed, we consider insulin, anti-hypertensives and genito-urinary system drugs (sex hormones and urological), which do not belong to the category " $\mathrm{N}$ - Nervous System" of the WHO Collaborating Centre for Drug Statistics Methodology. For these drugs, we use the ATC/DDD classification which standardizes the average drug doses for adults. As treating other pathologies, these prescription drugs should not be affected at all by the light cannabis availability. Estimates are reported in Table 4. All the DID coefficients are not statistically significant and very close to zero in magnitude. This provides further support to our main results in terms of causality.

To reduce any residual concern about possible violations of common trend assumptions, we also perform a permutation test based on a Monte Carlo simulation. The permutation test also allows us to explore the robustness of the results to assumptions about the structure of the error distribution. This is a strategy used in many empirical applications (e.g., Wing and Marier, 2014). Hence, we simulate the effect of local accessibility to light cannabis by randomly assigning the treatment to provinces at different points in time, in place of the real one. We repeat this 

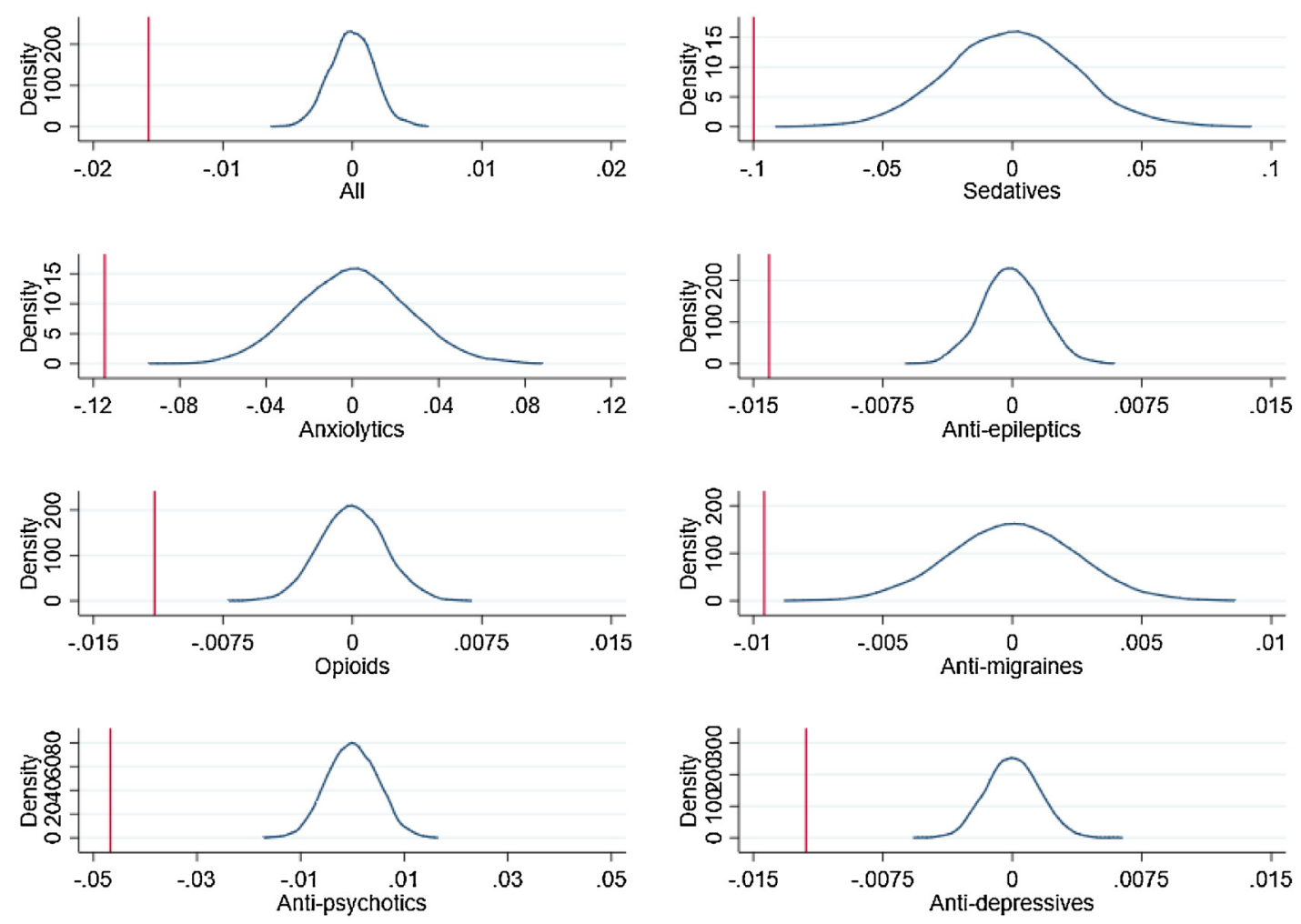

Fig. 5. Randomization inference.

The figures show the distributions of the placebo estimates based on 5000 permutations for all out outcomes separately. The vertical red lines represent the estimated coefficients in our baseline specification in Table 2.

Table 4

Robustness checks: placebo regressions.

\begin{tabular}{llll}
\hline & $(1)$ & $(2)$ & $(3)$ \\
& Insulin & Anti-hypertensives & $\begin{array}{l}\text { Sex Hormones and } \\
\text { Urologicals }\end{array}$ \\
\hline DiD & 0.015 & -0.002 & 0.006 \\
& 0.034 & 0.005 & 0.006 \\
Controls & yes & yes & yes \\
Year FE & yes & yes & yes \\
Month FE & yes & yes & yes \\
Province FE & yes & yes & yes \\
$N$ & 2756 & 2756 & 2756 \\
\hline
\end{tabular}

The drugs considered refer to the following ATC/DDD classification of the WHO Collaborating Centre for Drug Statistics Methodology: A10A (Insulin), C02 (Anti-hypertensive), G03 and G04 (Sex hormones, modulators of the genital system and Urologicals). Log transformation of the dependent variable. S.E. clustered at the province-level in italics.

procedure 5000 times to generate a distribution of placebo treatment effects. Fig. 5 presents the non-parametric distributions of these placebo estimates for all prescribed drugs included in our study, separately.

Fig. 5 shows that the average of the placebo treatments is zero and the actual coefficient, which is depicted by the red vertical line, falls far from the left tail of the distribution. As a result, this indicates that the negative and significant effect we find on drug prescriptions is very implausible to have occurred by chance.

Finally, to account for the recent developments in the econometric literature in the presence of a staggered rollout of the treatment (e.g., Athey and Imbens, 2018; Goodman-Bacon, 2018), we study the time-varying nature of the policy and the weights associated with its component. Following Goodman-Bacon (2018), we plot all the 2 $\times 2$ pairwise DID estimates (on the vertical axis) against their weights (on the horizontal axis). Fig. 6 indicates that the opening of a light cannabis shop led to a reduction in the sales of prescription drugs. The red line represents the weighted DID coefficient once accounting for the different weights associated to its component. Notably, the coefficients are all negative and qualitatively similar to our benchmark results. ${ }^{12}$

One can note the following two results. First, treated vs. never treated are the ones with the largest weight. For

\footnotetext{
12 Estimates shown in Fig. 6 are based on a seasonally-adjusted outcome variable in order to take into account the seasonal pattern in drug prescription. The original DiD accounts for the presence of month dummies, which are not implementable yet using the decomposition routines available in statistical software. Consequently, while the main sources of heterogeneity in the estimates can be assessed, point estimates are not directly comparable
} 

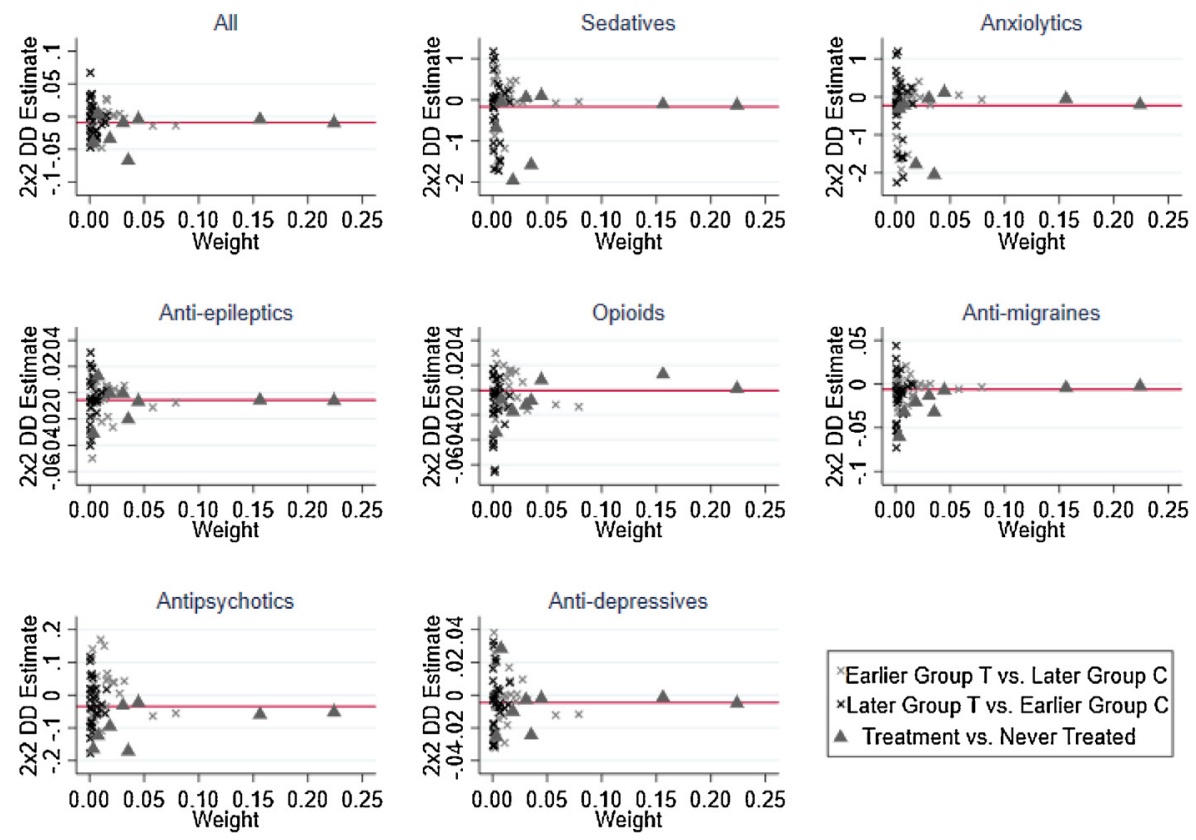

Fig. 6. $2 \times 2$ DiD Estimates (Goodman-Bacon Decomposition).

The figure plots each $2 \times 2$ DiD estimate against their weights calculated following the Goodman-Bacon (2018)'s decomposition for all prescription drugs considered in our model. The triangle refers to estimates where one timing group acts as treatment group and the never treated country as control group. The grey x's refer to timing-only estimates in which the early treated group acts as treatment group and the later treated group as control group. The black x's refer to timing-only estimates in which the later treated group acts as treatment group and the earlier treated group as control group. The red horizontal line refers to the weighted average DiD coefficient resulting from the Goodman-Bacon's decomposition.

instance, the weight associated with this group is always $52 \%$. This suggests that the latter is the main source of identification in our setting. Second, we note that while some $2 \times 2$ pairwise comparisons are positive, their weight is very close to zero. Thus, the average weighted DID coefficient is always negative for all our outcomes and, in some cases, this is even relatively larger. For example, in the case of sedatives, the average coefficient indicates a reduction in sales of- $0.16(-0.095$ in our baseline $\mathrm{DiD})$. In the case of anxiolytics, the average coefficient is $-0.22(-0.114$ in the baseline DiD). However, we take a conservative stance, interpreting the results from our main DID as a lower bound estimate.

\section{Event study}

To shed some further light on the observed substitution, we also explore the dynamic of patients' responses to local market availability of the new cannabis-light product. By exploiting a rather rare policy set-up with heterogeneous and staggering effects at a local level, our setting is ideal for studying patients' responses and for verifying the selfmedication hypothesis discussed above. We thus perform an event study analysis conceived as follows. We include in equation (1) a series of dummies coding the month in which entry in the market occurred and one to six months preentry and post-entry. One-month pre-entry is the excluded dummy for each dimension and is set equal to zero in our presentation of the results.

Results of the event study specification are reported graphically in Fig. 7. We find that reductions in the number of dispensed drugs occur since the second month after the entry of local retailers and it is more pronounced from the third month onwards. The figure also shows non-linearity in the substitution pattern but proves to be a statistically significant effect also in the six months following the local product availability. Importantly, Fig. 7 also shows that there is little evidence of systematic pre-trends affecting the results and this provides further support for the hypothesis of exogeneity in the cannabis light seller entry in each province. Lastly, looking at the magnitude of these effects, we find an average post-treatment coefficient of -0.015 . This is very close to our main DiD specification (column 1, Table 2). This suggests once again that timing heterogeneity is not driving our main results.

\section{Discussion}

Many countries worldwide have legalized or decriminalized marijuana for recreational and medical purposes. Others have recently legalized the cultivation for commercialization of hemp, an industrial strain of cannabis rich in CBD and almost free of psychoactive components. While on the one hand, this market is gaining momentum and is often described as the new "green oil", on the other hand, 


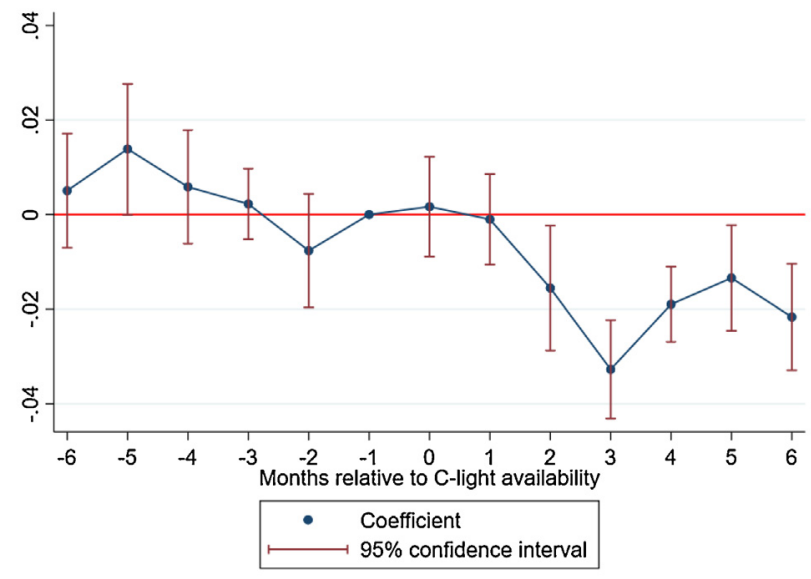

Fig. 7. Event study.

The figure presents an event study of the effects of local availability (represented by the red vertical line) on all dispensed drugs. One-month pre-entry is the excluded dummy for each dimension and is set equal to zero.

uncertainty is increasing among regulators and authorities about potential misuse. Given the uncertainty on how to govern this phenomenon and exploiting the difficulties in distinguishing light cannabis from illegal marijuana, several states such as Kansas, Louisiana, Texas and North Carolina opted for a tough stance by banning smokable hemp. Yet, this mostly unregulated market kept booming.

This paper provides a self-medication argument for such popularity by exploiting a unique opportunity offered by a loophole in the Italian legislation regarding the commercialization of a new CBD-based product. Indeed, we look at whether the availability of a new product suitable for self-medication impacted on dispensed drug sales to treat anxiety, psychosis, chronic pain, insomnia, migraine and epilepsy.

Using a staggered DiD model and considering monthly data for 106 Italian provinces during the period between January 2016 and February 2018, we find that the local availability of light cannabis led to a significant and large reductions of dispensed boxes of anxiolytics and sedatives, which amounted to approximately 10\%. These drugs usually treat symptoms for which CBD is often effective and for which a non-specialist can easily detect symptoms. We also find that the entry of a light cannabis retailer in a given province led a $1-1.5 \%$ reduction in the number of anti-epileptic, anti-depressant, opioid and anti-migraine prescriptions. In contrast, prescriptions for psychotic patients decreased by approximately $4-5 \%$. Much higher coefficients are more likely to emerge when considering a more extended time window. Indeed, our coefficient indicates a lower bound for the effect of light cannabis on prescription drugs. In contrast, no substitution effect was found for prescription drugs without relaxant effects, such as insulin, hypertensives, as well as sex hormones and urological.

Our results are compatible with a self-medication hypothesis, that is, the adoption of risky behaviors to seek a quality of life improvements and relief. Indeed, the large-scale accessibility to the new product, which was advertised as a relaxant one, induced some patients to abandon traditional medicine to seek relief. Selfmedication arises as the product was neither suitable for medical purposes nor was allowed to be consumed. This renders less likely that the substitutional patterns we observed were driven by medical advice. As discussed, light cannabis liberalization was due to a legislative void and, for this reason, unannounced and not capable of creating an anticipatory effect, therefore reducing the likelihood of "off the record" medical advice. Our estimates assume more relevance when considering the relatively short time window we consider, that is 10 months after the policy was implemented, the lack of clinical support, and the unusual way in which light cannabis was made available as well as our focus on a short period after the introduction of the product. Patient response to new drugs and therapies is usually heterogeneous and sluggish because of typical risk aversion. Nonetheless, we find a significant and negative effect on several drugs treating pathologies for which medical cannabis (and not light cannabis) has demonstrated some degree of effectiveness.

The event study also provides additional insights into patients' responses. We observe that substitutional patterns are more accentuated starting from the third month after the entry of the first light cannabis retailer in the local area and significant also after six months post entry. This result may indicate that individuals started substituting therapy after some weeks of experimentation or just after realizing that the new product had become locally available, thereby reinforcing the "rational" characterization of self-medication. In this sense, the paper provides a selfmedication explanation, different from "hype-seeking" for the explosive success of cannabis-derived products, even in the absence of the psychoactive compound (THC), in the US and Europe.

Finally, our estimates present a series of important public policy implications that go beyond Italy's case. First, the substitution we identify may stem from the patients' needs of more effective relief, which is not currently addressed 
by traditional medicine. This configures a form of market failure that lawmakers should account for. One way could be to improve the current distribution channel of medical marijuana. Absent any further policy change in this direction, our study suggests that policies such as a ban on light cannabis, as promoted by several US states and by Italian policymakers in 2019, might eventually decrease patients' welfare as disregarding their needs for more effective relief.

Second, forms of self-medication may, at first, ring the alarm bells of policymakers as individuals may not follow expert advice even when taking care of their health. Our results suggest that regulatory authorities should be cautious and vigilant as the large-scale availability of light cannabis may induce substitution patterns not clinically validated. Moreover, our study highlights that regulation of light cannabis is required. In a similar vein, a more general public health campaign should complement such a policy. For instance, instructing doctors and providing labels and certification alongside information regarding doses for these products may be a first attempt to make light cannabis, and in general CBD-derived product consumption, much more controlled.

Third, from a public policy perspective, we observe that the shift in consumption from traditional drugs to light cannabis came from a non-negligible cost for a patient. This is because, unlike the drugs we consider, which are either fully reimbursed by the Italian NHS or subject to a small co-payment from a patient, light cannabis is often sold at 8-10 euros per gram. This suggests that the unintended policy liberalization led to an unexpected contraction of pharmaceutical expenditure, ceteris paribus. As pharmaceutical expenditure worldwide has rapidly increased in recent years and this is equally true in Italy (Federfarma, 2018), the presence of such short-term financial benefits should be considered among the other welfare effects of this unintended policy experiment.

\section{Acknowledgments}

We thank the Editor Maarten Lindeboom and two anonymous referees for insightful and detailed comments. We are grateful to Anna-Katharina Böhm, Davide Dragone, Sandy Tubeuf, and Jan C. van Ours, participants at the NHESG 2019 Conference (Iceland), the Italian Association for Health Economics (AIES, Pisa 2019), the First Bolzano Applied Microeconomics Workshop (2019), alongside seminar participants at the University of York, University of Pavia, and at the Erasmus School of Economics for helpful comments on previous drafts of the paper. Finally, we also thank Andrea Agnello for assistance over the use of data and Walter Vigna. Usual disclaimers apply. Leonardo Madio acknowledges funding from the European Research Council (ERC)under the European Union's Horizon 2020 research and innovation programme (grant agreement No 670494) and from the French National Research Agency (ANR)under the Investments for the Future programme (Investissements d'Avenir, grant ANR17-EURE-0010).

\section{Appendix A. Supplementary data}

Supplementary material related to this article can be found, in the online version, at doi:https://doi.org/10.1016/j.jhealeco.2020.102371.

\section{References}

Anderson, M.D., Hansen, B., Rees, D.I., 2013. Medical marijuana laws, traffic fatalities, and alcohol consumption. J. Law Econ. 56 (2), 333-369.

Athey, S., Imbens, G.W., 2018. Design-Based Analysis in Difference-in-Differences Set- Tings With Staggered Adoption. NBER Working Paper 24963. National Bureau of Economic Research.

Bachhuber, M.A., Saloner, B., Cunningham, C.O., Barry, C.L., 2014. Medical cannabis laws and opioid analgesic overdose mortality in the United States, 1999-2010. JAMA Intern. Med. 174 (10), 1668-1673.

Baggio, M., Chong, A., Simon, D., 2020. Sex, drugs, and baby booms: can behavior overcome biology? J. Health Econ., Forthcoming.

Baltagi, B.H., Griffin, J.M., 2002. Rational addiction to alcohol: panel data analysis of liquor consumption. Health Econ. 11 (6), 485-491.

BDS Analytics, Available at: 2019. U.S. CBD Market Anticipated to Reach $\$ 20$ Billion in Sales by 2024

https://bdsanalytics.com/u-s-cbd-market-anticipated-to-reach-20 -billion-in-sales-by-2024/.

Becker, G.S., Murphy, K.M., 1988. A theory of rational addiction. J. Polit. Econ. 96 (4), 675-700.

Becker, G.S., Grossman, M., Murphy, K.M., 1994. An empirical analysis of cigarette addiction. Am. Econ. Rev. 84 (3), 396-418.

Blessing, E.M., Steenkamp, M.M., Manzanares, J., Marmar, C.R., 2015. Cannabidiol as a potential treatment for anxiety disorders. Neurotherapeutics 12 (4), 825-836.

Bradford, A.C., Bradford, W.D., 2017. Medical marijuana laws may be associated with a decline in the number of prescriptions for Medicaid enrollees. Health Aff. 36 (5), 945-951.

Bradford, A.C., Bradford, W.D., 2018. The impact of medical Cannabis legalization on prescription medication use and costs under medicare part d. J. Law Econ. 61 (3), 461-487.

Bradford, A.C., Bradford, W.D., 2016. Medical marijuana laws reduce prescription medication use in medicare part d. Health Aff. 35 1230-1236.

Carrieri, V., Madio, L., Principe, F., 2019. Light cannabis and organized crime: evidence from (unintended) liberalization in Italy. Eur. Econ. Rev. 113, 63-79.

Case, A., Deaton, A., 2015. Rising morbidity and mortality in midlife among white non-hispanic americans in the 21 st century. Proc. Natl. Acad. Sci. 112 (49), 15078-15083.

Cawley, J., Ruhm, C.J., 2012. The economics of riskyhealthbehaviors. Chapter 3. In: McGuire, Thomas G., Pauly, Mark V., Barros, Pedro Pita (Eds.), Handbook of Health Economics, Vol. 2. Elsevier, New York, pp. 95-199.

Červený, J., Chomynová, P., Mravčík, V., van Ours, J.C., 2017. Cannabis decriminalization and the age of onset of cannabis use. Int. J. Drug Policy 43, 122-129.

Chaloupka, F., 1991. Rational addictive behavior and cigarette smoking. J. Polit. Econ. 99 (4), 722-742.

Chan, N.W., Burkhardt, J., Flyr, M., 2020. The effects of recreational marijuana legalization and dispensing on opioid mortality. Econ. Inq. 58 (2), 589-606

Chang, T.Y., Jacobson, M., 2017. Going to pot? The impact of dispensary closures on crime. J. Urban Econ. 100, 120-136.

CIBG, Available at: 2018. Report on Medical Cannabis in the Netherlands. Office for Medical Cannabis.

https://english.cannabisbureau.nl/medicinal-cannabis/documents/ circulars/2018/02/20/patients-guide-medicinal-cannabis.

Crost, B., 2012. The effect of alcohol availability on marijuana use: evidence from the minimum legal drinking age. J. Health Econ. 31 (1), 112-121.

Cunningham, S., Shah, M., 2018. Decriminalizing indoor prostitution: implications for sexual violence and public health. Rev. Econ. Stud. 85 (3), 1683-1715.

Darden, M.E., Papageorge, N.W., 2018. Rational Self-Medication (No. w25371). National Bureau of Economic Research.

Dinardo, J., 2001. Alcohol, marijuana, and american youth: the unintended consequences of government regulation. J. Health Econ. 20 (6), 991-1010. 
Dragone, D., 2009. A rational eating model of binges, diets and obesity. J. Health Econ. 28 (4), 799-804.

Dragone, D., Prarolo, G., Vanin, P., Zanella, G., 2019. Crime and the legalization of recreational marijuana. J. Econ. Behav. Organ. 159, 488-501.

FDA, Available at: 2019. FDA Regulation of Cannabis and Cannabis-derived Products: Questions and Answers. https://www.fda.gov/news-events/public-health-focus/fda-regulation -cannabis-and-cannabis-derived-products-questions-andanswers\#farmbill.

Federfarma, 2018. La Spesa Farmaceutica Nel 2017. Analisi Dell'andamento Della Spesa Farmaceutica Convenzionata a Livello Nazionale E Regionale.

Gavrilova, E., Kamada, T., Zoutman, F., 2017. Is legal pot crippling Mexican drug trafficking organisations? The effect of medical marijuana laws on US crime. Econ. J. 129 (617), 375-407.

Goodman-Bacon, A., 2018. Difference-in-Differences With Variation in Treatment Timing. NBER Working Paper 25018. National Bureau of Economic Research.

Grossman, M., Chaloupka, F.J., 1998. The demand for cocaine by young adults: a rational addiction approach. J. Health Econ. 17 (4), 427-474

Hansen, B., Miller, K., Weber, C., 2020a. Early evidence on recreational marijuana legalization and traffic fatalities. Econ. Inq. 58 (2), 547-568.

Hansen, B., Miller, K., Weber, C., 2020b. Federalism, partial prohibition, and cross-border sales: evidence from recreational marijuana. J. Public Econ. 187, 104159.

ISTAT, Available at: 2018. La Salute Mentale Nelle Varie Fasi Della Vita. ISTAT 2018 - Anni 2015-2017. https://www.istat.it/it/archivio/219807.

Liang, D., Bao, Y., Wallace, M., Grant, I., Shi, Y., 2018. Medical cannabis legalization and opioid prescriptions: evidence on US Medicaid enrollees during 1993-2014. Addiction 113 (11), 2060-2070.

McMichael, B.J., Van Horn, R.L., Viscusi, W.K., 2020. The impact of cannabis access laws on opioid prescribing. J. Health Econ. 69, 102273.
Mercuri, A.M., Accorsi, C.A., Mazzanti, M.B., 2002. The long history of Cannabis and its cultivation by the Romans in central Italy, shown by pollen records from Lago Albano and Lago di Nemi. Veg. Hist. Archaeobot. 11 (4), 263-276.

National Academies of Sciences, Engineering, and Medicine, Report released on January12, 2017 2017. The health effects of cannabis and cannabinoids: the Current State of Evidence and Recommendations for Research.

Powell, D., Pacula, R.L., Jacobson, M., 2018. Do medical marijuana laws reduce addictions and deaths related to pain killers? J. Health Econ. $58,29-42$

Sabia, J.J., Swigert, J., Young, T., 2017. The effect of medical marijuana laws on body weight. Health Econ. 26 (1), 6-34

Shy, Y., 2017. Medical marijuana policies and hospitalizations related to marijuana and opioid pain reliever. Drug Alcohol Depend. 173, $144-150$.

Smith, R.A., 2020. The effects of medical marijuana dispensaries on adverse opioid outcomes. Econ. Inq. 58 (2), 569-588.

The New York Times, July 4, 2019. Available at: 2019. North Carolina Proposes Smokable Hemp Ban As Demand Grows. https://www.nytimes.com/aponline/2019/07/04/us/ap-us-smokablehemp-bans.html.

Van Luijk, E.W., Van Ours, J.C., 2001. The effects of government policy on drug use: java, 1875-1904. J. Econ. Hist. 61 (1), 1-18.

Van Ours, J.C., 1995. The price elasticity of hard drugs: the case of opium in the Dutch East Indies, 1923-1938. J. Polit. Econ. 103 (2), 261-279.

Wen, H., Hockenberry, J.M., Cummings, J.R., 2015. The effect of medical marijuana laws on adolescence and adult use of marijuana, alcohol, and other substances. J. Health Econ. 42, 64-80.

Wing, C., Marier, A., 2014. Effects of occupational regulations on the cost of dental services: evidence from dental insurance claims. J. Health Econ. 34, 131-143. 